\title{
THE PSYCHOSOCIAL ASPECTS OF TEAM SPORTS: THE INDIVIDUAL VERSUS THE TEAM
}

\author{
Halina Zdebska \\ Academy of Physical Education, Cracow, Poland
}

\begin{abstract}
Halina Zdebska. Doctor of Physical Culture Sciences at the Department of Theory and Methodics of Team and Recreational Sports, Academy of Physical Education. The field of scientific research — psychosocial aspects of sports.

ABSTRACT

This text is a part of a longer elaboration concerning the humanistic bases of the theories of team sports. The notion "sports games" refers to team sports, which are most popular in our culture (in Poland): volleyball, basketball, football and handball.

Team sports are a very interesting matter for the observation, how the integrated human teams function. Sport, as a constituent of social life, is liable to the principles and rules, which are similar to the ones we may observe in ambient reality. Willing to explain and describe those phenomena, we should reach for the knowledge from the subject field of social sciences; in this case - concerning the collective behaviours.

In this analysis I took into consideration the opinions about the functioning of human communities - the opinions formulated by G. Le Bon (1996), W. McDougall (1920), S. Freud (2000) and selected conceptions from contemporary American psychology concerning the relations between the individual and the group. In this context I emphasized a reflection about the necessity of proper stimulation, when the development of an individual is concerned, which means the change towards the individualization of training in team sports. The character of this text is strictly theoretical but it is also an attempt to accentuate the importance of the knowledge of a team's morphology and the relations between an individual and other members of a team for sports practice. This knowledge is a substantial (but usually underrated) element of the trainer's work.
\end{abstract}

Keywords: team sports, collective behaviours, philosophy, psychology of sport, role of trainer, team building.

\section{INTRODUCTION}

$\mathrm{K}$ nowledge related to the morphology of a team and also the relations between an are really important (but usually underrated) part of the trainers" "workshop". Sport, as a constituent of social life, is liable to the principles and rules, which are similar to the ones we may observe in ambient reality. Willing to explain and describe those phenomena, we should reach for the knowledge from the subject field of social sciences; in this case - concerning the collective behaviours.

The main aim of this article is to analyse the opinions about the functioning of human communities. The opinions formulated by G. Le Bon (1996), W. McDougall (1920), S. Freud (2000) and selected conceptions from contemporary American psychology concerning the relations between the individual and the group. In this context I emphasized a reflection about the necessity of proper stimulation, when the development of an individual is concerned, which means the change towards the individualization of training in team sports. The character of this text is strictly theoretical but it is also an attempt to accentuate the importance of the knowledge of a team's morphology and the relations between an individual and other members of a team for sports practice. 


\section{DISCUSSION}

Gustave Le Bon's "psychology of a group". G. Le Bon (1996) - the forerunner of this field of research, which is situated at the boundary of Social Psychology and Sociology, published in 1895 "The Mob Psychology", where he defined the psychology of a community or studying collective behaviours.

There are contradictory views related to the correctness of the notion of "psychology of a group" or "psychology of a community" and this question hasn't been settled yet (Le Bon, 1996). The opponents emphasize that the members of a given community may think alike, feel alike but it's still not enough to jump to conclusion, which would prove the existence of collective psyche. The author presents the features of the mob, which differ it from a set of individuals taking part in it. The G. Le Bon's "mob" has meaning, which is different from a traditional understanding of this conception" (Le Bon, 1996). "At the convergence of some circumstances and only in those circumstances the community gains completely new features, different from the ones that the particular individuals, which in this case comprise the mob, have. While being a part of a mob, the consciousness of own individuality dwindles and the feelings and thoughts of everybody have the same direction. The collective soul seems to emerge; it's existence is undoubtedly very short but it has some characteristic features, which are extraordinarily distinct" (Le Bon, 1996). From the one's point of view the affiliation to the mob isn't a beneficial effect due to the fact that " $<\ldots$... in the collective soul the intellectual features and individuality of a human individual fade. The heterogeneity turns into homogeneity and the unconscious features play the main role here. $<\ldots>$ the mob means accumulation of mediocrity, never intelligence" (Le Bon, 1996).

The basic feature of a human community, which is specified as "psychological mob" (or in other words - organized mob), is "the rule of mental unanimity". According to this rule, the mob shares the same feelings and one main leading idea.

The mob easily undergoes alterations: the thoughts and feelings may often change, e. g. the heroic, revolutionary mob under the influence of

\footnotetext{
${ }^{1}$ Usually „mob” means a community of accidental individuals, their nationality, gender or religion don't matter as well as the event which gathered them.
}

some stimuli may turn into the conservative mob. Moreover, the lack of durability is typical of it. It can't be persistent in pursuing its aim, especially when some obstacles appear. The feelings, which are expressed by the mob are usually exaggerated, extreme, sometimes even supported by detrimental and violent behaviours. The mob doesn't tolerate opinions that are different than its own.

Having mentioned the problem of characteristic of a mob as a whole, G. Le Bon (1996) made also an attempt to present behaviours and psychological processes of the individuals belonging to a mob. Affiliation to a mob gives the feeling of power. " $<\ldots$.. every single individual, even under the influence of the size of a mob only, gains the feeling of invincible power, which lets them express their passions, surely suppressing when they are alone. They will not control themselves because the sense of responsibility, which always curbs them, disappears from their souls; the mob is always anonymous and thus irresponsible" (Le Bon, 1996). This seeming sense of power leads in consequence to desindividualization, which may build the illusion of impunity. The number of individuals who participate in the mob but are able to resist the prevailing atmosphere and suggestion of the rest is slender. The rule says: if you are one of us you have to surrender to the mood of a mob. "The contagion of feelings and act controls the individual so much that one may sacrifice their personal aims to follow the common idea. This feature is against the human nature but everyone is susceptible to performing that way when they become the participants of a mob" - claims G. Le Bon (1996).

Following the moral standards is hindered in a mob as it is changeable and vehement. Nevertheless were there some proves that in parallel to violent and cruel instincts the mob afforded sometimes very elevated moral acts. The history knows the cases of the mobs, which died heroically defending an idea, creeds, etc. There are also some proves for the moral influence of the mob (e. g. during the French Revolution some members of criminal groups gave the money and jewellery, which were taken from their victims to the revolution committees). "Usually the private business is the main factor that makes the individual act whereas in the mob it is really insignificant" - remarks G. Le Bon (1996). The mob may be liable to low instincts or reveal the elevate moral merits. The morality of a mob isn't realized (The mob itself isn't able to reason), 
however, it has an incredible imagination (e. g the picturing a great victory, crime, hope, etc., which are very suggestive) that gives the full control of the mob, the power. Every mob has its own leader. His authority is indisputable, he knows how to awaken the faith and be the guide. The soul of a mob isn't directed by the need of freedom but the need of yielding to something or somebody. This need of obedience and affiliation force an individual to surrender and follow anyone who wants to rule. The leader must be distinguished by prestige (personal or acquired).

To recapitulate - a mob doesn't yield any benefits as far as the matter of the individual development is concerned, even more - the individual who becomes a participant of a community goes down the ladder of civilization.

Thesis of G. Le Bon versus team games. Trying to maintain a distance to this thesis (the later research in field of social sciences verified this matter without any problem) we should notice that selected plots G. Le Bon's (1996) conception are related to general meaning of social behaviours. It has been a rich source of references made by many researchers dealing with this issue (Lindsey, 1954; Lindsey, Aronson, 1969; Turner et al., 1957).

It's important for the conducted analysis to emphasize that maintained features are typical for the brief events created as a community of various individuals connected by a momentary interest. In contrary, the sports team is a stable community consisting of different (but properly selected) individuals, who owe the particular abilities and qualifications to perform a task (morphological and psychical features coupled with technical and tactical skills). The main idea which connects the teams members is cooperation and competition with other similar teams. They compete for the victory, which results in prestige, fame and often even money. In contrary to a mob, the team performs consciously and belonging to a group doesn't cause the disindividualization of players. The engagement in action requires also some intellectual work. We meet here (like in every sports games) motion open habits where the main role play cognitive and decisional processes (perception, recognition of a stimulus and selection of reaction). It's possible to react differently for the same stimulus using the system of experiences and operational thinking. The player may follow one out of a few patterns of performing when he faces the same situation. The game takes place according to a kind of convention and the access to participation is a consent to observe the compulsory norms and regulations (legal, e. g. the rules and moral, e. g. fair play). This we may include that an affiliation to this kind of community influences an individual very positively in contrary to the situation with a mob. The contagion of feelings is worth devoting our attention - we often observe it in the reactions of players (the joy after a well performed action, when they win or the sadness after suffering a defeat, etc.). It is a proof for the fact that the team thinks and feels in the cathegories of "WE". The joy and enthusiasm of the whole group (not excluding the second team) comprise the "good spirit" of a team.

Aside from the observations that are described above, it seems that in search for the explanation of the functioning of a team we should go towards the conceptions of more stable and better organized communities than G. Le Bon's (1996) "mob".

Community versus Ego. The questions about a "psychological community", the way it gains the power to influence the individual's life so much and about the essence of this psychological change, which is imposed on an individual, were asked by Sigmund Freud (2000), the inventor of psychoanalysis. He treats a human being as a part of a tribe, a nation, a caste, a state, an institution or any other human community, which in particular time and with a particular purpose organizes and makes the community. "This extracting of an individual from their natural context would let assume that the phenomena occurring in these particular conditions are separate symptoms of a social impulse, which can't be compared with anything - herd instinct, group mind - which in other situations isn't revealed (Freud, 2000).

The unification of a level of all "collective people" (Massenindividuen) is a result of abolishing the features, inhibitions characteristic for a particular individual and resignation from their specific propensities. To explain the psychology of a community, he used a conception of libido (derived from the theory of affects). This name defines some " $<\cdots>$ quantitative dimension - it can't be measured - the energy of the impulse, which are connected with what we call love" (Freud, 2000). He made an assumption that emotional connections (more neutral conception) also make a part of the psyche of a mob. The coherence of a mob 
is dependent on some power and according to S. Freud (2000) Eros keeps everything in coherent whole. The second premise, which was the basis of his assumptions, was the conviction that if an individual resigns from their individuality in a mob they prefer to be in harmony with the rest than have a conflict, they perform "to the satisfaction of a mob" (,ihnen zu liebe") (Freud, 2000).

When we analyze two artificial communities: a catholic church and an army, he comes to a conclusion of libidinal structure of a community. In his research he took into a consideration, e. $g$ phenomena of panic in military masses. If the individuality starts to take care only about themselves, it's a proof for the fact that they noticed that the affective bonds, which in their opinion had reduced danger, are broken away - he writes - if an individual has to face the danger alone, they may indeed overrate it." $<\ldots>$ the fear is a result of looseness of the libidinal structure of a mob and it's an excused reaction for it, not inversely - the fear of danger doesn't slacken and break the libidinal bonds, which exist in a community" (Freud, 2000).

The libidinal bonds are supposed to characterize a community. Therefore, what are the affective attitudes that people adopt towards each other? Probably it's like in A. Schopenhauer's parable about freezing porcupines, nobody likes when others are excessively ${ }^{2}$ (Freud, 2000).

The psychoanalysis proves that every single emotional relationship, which lasts longer (e. g. marriage, friendship, etc.) also contains some shadow of negative feeling, we don't notice it as we suppress it. However, during the process of forming a community and in a community itself, this intolerance disappears until the individuals behave as if they were identical, equal. „The only barrage for a love to oneself may be a love towards the things which are strange and unfamiliar, a love towards objects (Freud, 2000). But is it possible that common business is a sufficient reason to limit narcissism and to tolerate another human being? This tolerance usually lasts for as long as deriving profits from this cooperation with others is possible. However, during this cooperation it

\footnotetext{
${ }^{2}$ „On a frosty winter day a few porupines gathered closly to warm each other. Soon afterwards they started to prickle one another so they scurried again. However the need of warmth forced them to gather one more time - then the same unpleasantness met them. They repeatedly went from one extreme to the other to chose the lesser of two evils and finally they found the proper distance, which pleased them all."
}

comes to creation of libidinal bonds, which protract durability of this relationship, independently from the profits. In social relations proceeds exactly the same evolution of libido as in the individual. "The libido forces us to meet our basic needs and it chooses the people, who participate in this satisfying as it's first objects" - he writes.

We owe the psychoanalysis the knowledge that there are other mechanisms of emotional bonds so-called identifications. An identification makes the most primary kind of an emotional bond. It may appear as soon as we have noticed the occurrence of some special common feature in the personality of an individual who is a subject of our sexual impulses. The importance of this feature in interhuman relations prevails as far as the efficiency of identification and creating a new emotional bond is concerned: the empathy (entrance into the spirit, understanding) S. Freud's (2000) libidinal structure of community refers to a special kind of community - with a leader - and it can't gather again the characteristics of an individual due to the excess of "organisation"

The theory of libido tells us also about a propensity of all living creatures to associate in greater units. These psychical phenomena are called "herd instinct" by W. Trotter (1916), who describes it as a primary and indivisible feature. An individual feels incomplete when it remains alone (Trotter, 1916).

The quintessence of S. Freud's (2000) opinions includes in conviction that every single individual as a component of many communities is multilaterally bound by identification and that it has its own idea of Ego, which is built according to complicated patterns. Participating in many "collective psyches" (e. g. race, state, nation), an individual may ascend over them — they achieve a bit of independence and originality.

W. McDougall (1920), who is an author of "The Group Mind" (McDougall, 1920), characterizes there communities, which are highly organized. He enumerates five principal conditions, which when fulfilled let raise the psychical life of a mass on a higher level. When we take into consideration interdependencies between players (so distinct from e. g. a team of swimmers or a team of athletic relay racers) we may certainly

\footnotetext{
${ }^{3}$ The analise of psychoneurisis, which was conducted among the soldiers of German army during the time of World War I, proved that the source of those diseases was internal and embraced the fact that the soldiers were treated badle by the oficers, which was a reason of attenuation of the army.
} 
qualify a sport team (organization of team is considerated) to this category. These conditions are to prevent arising of negative effects of forming a group (they were signalled by G. Le Bon (1996)):

1. Attainment of a certain degree of continuity in the group's composition (the same people are members for a longer period of time);

2. Forming of a particular notion, which give to an individual an idea of their functions, achievements and requirements made by a group to create an emotional attitude towards the group as a whole;

3. Entrance of a group into relations with other, similar but in a way different creations (during the competition);

4. Possessing it's own traditions, habits and organization of a group, especially the ones which are related to mutual relations of the members;

5. Segmentation of a group, which follows the specialization and diversification of tasks given to an individual.

The fact that problem solving is given to individuals not to a group as a whole prevents a decrease in collective intelligence. This kind of organization of group is characterized by S. Freud (2000) differently. "The task consists in recreating some features of an individual, which were characteristic for them but were destroyed by the process of adjustment to a group. This individual had - beyond a primitive group - their continuity, self consciousness, traditions, habits, particular achievements in work and also a position and they were visibly separate from others, whom they competed with" (Freud, 2000).

If libidinal bonds characterize a community, is deriving a profit from cooperation with others a sufficient reason of their origin in sports teams? Do they always exist and bind the individualities, which make a team, in equal extend? As we know, the positive attitude towards the group as a whole doesn't mean positive feelings to every single member of a team. And what a team is conflicted but still wins, and vice versa, when there is a wonderful atmosphere but no intended results? This state is probably a result of the fact that the occurrence of those bonds isn't a determining factor but only one of the components. It's certain that the bonds easier trainer's work and managing a team. R. B. Maddux (1988) emphasizes that most of the trainers would choose players that cooperate with each other harmoniously, according to rules that a team with good interhuman relations is more likely to whim than a team of conflicted stars. The proverb says: "champion's-team always defeats a team of champions (stars)". In general the team must strive for positive climate. Selection of people, who are able to cooperate well with others is a staple of a success and creating efficient team.

Meeting personal needs (aims) of group's members and achieving maximally high results in one time is a very difficult task. The best players (the most efficacious ones) usually strive for high results and resignation from their own individualities, scarifying it for the team may be also difficult or even impossible (it is very visible at the level of professional teams where deriving profits from games takes place). However, the compromise is possible as the example of Michael Jordan and "Chicago Bulls" shows. " $<\ldots>$ the team won NBA championship scarcely a year after the time of problems, when other players tried to accept the dominating presence of superstar Michael Jordan, and Michael himself struggled with a problem, how to play with less gifted colleagues from a sports club. That was a great challenge for the trainer - Phil Jackson, who needed to take full advantage of Jordan's talents but also let other players influence results of a game. " <...> if we let Jordan do whatever he wanted, he would probably score 50 or even more points but other players wouldn't be able to play and our system of defence would be predictable, thus the team would play less efficient than it may perform. During a first few months they played in exactly that way. Jordan played as a superstar but the "Bulls" didn't manage to be champions. The team transformed in a champion's-team soon afterwards as Jordan managed to adjust himself to a new role, which consisted in cooperation with team colleagues " (Morris, Summers, 1998).

\section{CONCLUSIONS}

Large extent of knowledge about building a team comes from a world of business. T. J. Peters and R. H. Waterman (1994) proved that basic meaning of a success, achieved by the best companies in branch, was grounded on a system of values. "Every perfect company, we examined, was aware of what it represented and treats seriously the values, it prefers. Indeed, we wonder, whether it is possible to create an outstanding company without any special convictions formed on a ground of 
positive values" (Morris, Summers, 1998).

The conviction that a team must be more important than an individual is quite common among trainers and it causes that the needs of an individual rarely draw proper attention. Communication usually takes place at the level of group. Trainers often forget that every member of a group wants to have their own, visible contribution to task solving. If we want players to resign from their own ambitions for the sake of a team, we have to talk about it to them. If there's no compromise between a trainer and a player, we can't expect any engagement in realization of a task during a game. Praising and approbation of individual merits should take place during discussing concrete situations as well as during every day interactions.

These remarks are directly related to a role of a trainer and a style of working with a team. T. Morris and J. Summers (1998) emphasize that from a moment of selection a team the trainer should strive for maximalization of a team's achievements. This process is very folded and doesn't guarantee that the needs of an individual and the team will always be concurrent. Team building is a way of creation by thinking to understand, respecting compromises of individuals making the team but first of all it consists in finding a way to develop an individual in frames of structure of efficient team (Morris, Summers, 1998). Functioning in a team means responsibility and making decisions. We often observe the behaviours of trainers, which prove that the coach doesn't trust his players and at the same time he doesn't regard them as separate individuals. "An irritated, raving trainer, who doesn't control the situation, shouts at his players but certainly he doesn't do anything to decrease excessively high level of excitation. He can't rate the situation, not to mention an inability to give a reasonable advice" - writes Z. Czajkowski (1996). Also constant advice given to a player by a trainer and other members of a team are very detrimental. Not only do they raise excitement to excessively high level but also kill independence and responsibility " $<\ldots$.. $>$, they retard reactions for the activities of an opponent. $<\ldots>$ the occurrence of this habit is very persistent as well as burning grass, which doesn't raise the level of fertility of a soil but often destroys useful creatures and leads to fires and misery. With gallows humour we may say that excessive exiting of a player and constant advises are equally detrimental and stupid as burning the fields" (Czajkowski, 1996).

The new theories of guidance and managing (human relations management theory), emphasise the importance of more democratic style of control and of the participation of interested individuals in making decisions. James Counsilman - a famous trainer and psychologist - claims: "The trainers usually want their contestants to identify with them and it is even better when they all identify with a common aim" (Czajkowski, 1996).

Now, it is only to translate it into the language of sports ordinariness. How to do it? At first the abhorred yoke of "teamness" must be lifted from the field of sports games. Then there should be a turn to the individualization of a training, which lets the individual be stimulated and developed properly.

\section{REFERENCES}

Le Bon, G. (1996). The Mob Psychology. Warsaw: PWN. Czajkowski, Z. (1996). Psychology - the Ally of a Trainer. Warsaw: COS. P. 73.

Freud, S. (2000). Beyond the Pleasure Principle. Warsaw. P. 192.

Lindsey, G. (Ed.) (1954). Social Psychology, II. Cambridge: Addison - Wesley.

Lindsey, G., Aronson, E. (Eds.) (1969). The Handbook of Social Psychology. Vol. IV. Menlo Park, London: Reading Mass.

Maddux, R. B. (1988). Team Building: An Exercise in
Leadership. Menlo Park, Ca: Crisp Publications.

McDougall, W. (1920). The Group Mind. Cambridge.

Morris, T., Summers, J. (1998). The Psychology of Sport. P. 190.

Peters, T. J., Waterman, R. H. (1994). The Frontiers of Excellence - Learning from the Companies that Put People First. London: Nicholas Brealey Publishing.

Trotter, W. (1916). Instincts of the Herd in Peace and War. London.

Turner, R. H., Killian, L. M. (1957). Collective Behaviour. Englewood Cliffs (N. Y.): Prentice-Hall.

Halina Zdebska

Department of Theory and Methodics of Team and Recreational Sports Academy of Physical Education in Cracow

31-571 Kraków

al. Jana Paw ${ }^{3}$ a II 78

Poland

Tel +48/12/683 1281

E-mail hzdebska@interia.pl 